\title{
Cost-Benefit AHPSort for performance analysis of offshore providers
}

\author{
Alessio Ishizaka ${ }^{1}$ and Cristina López ${ }^{21}$ \\ ${ }^{1}$ University of Portsmouth, Portsmouth Business School, Centre for Operational Research and \\ Logistics. Richmond Building, Portland Street, Portsmouth PO1 3DE, United Kingdom, E-mail: \\ Alessio.Ishizaka@port.ac.uk \\ ${ }^{2}$ University Pablo de Olavide, Faculty of Business. Pedro R. Campomanes Building, Utrera Road, \\ km. 1 -41013 Seville, Spain, E-mail: clopvar@upo.es
}

\section{ABSTRACT:}

The performance of a company is largely affected by that of its providers as they are a direct factor that determines product prices, flexibility and quality. It is therefore important to measure their performance. Several aspects need to be measured but traditional multi-criteria decision methods (MCDM) do not benchmark but only rank providers. Multi-criteria decision sorting methods are well indicated to benchmark activities into classes. In this paper, we present a modification of the AHPSort sorting method, where cost and benefit criteria are kept separate for a better and easier comparison. A case study in the aerospace industry will illustrate the efficacy of the new Cost-Benefit AHPSort method. The results will help managers to make specific decisions concerning their current offshore providers. They will also give valuable feedback for providers in order to improve their performance. Additionally, the findings enable a definition of benchmarking that will support future evaluations.

Keywords: Offshore outsourcing decisions; Benefit, Cost; AHPSort, Provider evaluation.

\section{Introduction}

Outsourcing has become a key strategic component to compete in terms of costs, flexibility and responsiveness (Gunasekaran and Irani 2010). As several criteria need to be considered for selecting an outsourcing partner, multi-criteria decision methods (MCDM) have been largely used to support the provider selection process, such as the Analytic Hierarchy Process (AHP) (Ishizaka 2008), the Analytic Network Process (ANP) (Asadabadi 2017), fuzzy AHP (Ishizaka 2014), fuzzy ELECTRE (Sevkli 2010), TOPSIS (Kasirian and Yusuff 2013), a coupling of fuzzy AHP and fuzzy TOPSIS (Kaur, Singh, and Majumdar 2018), etc. A review of decision-making methods used for provider selection can be found in (Chai, Liu, and Ngai 2013). However, the provider selection is only the first step of the outsourcing process and the relationship needs to be managed (Ishizaka and Blakiston 2012). In

\footnotetext{
${ }^{1}$ Corresponding author: Cristina López. Tel.: +00-34-95-4977324; fax: +00-34-95-4348353. E-mail address: clopvar@upo.es
} 
order to do so, it is important to measure the provider's performance. Performance needs to be benchmarked against targets measured through several criteria (Ihrig, Ishizaka, and Mohnen 2017). The traditional MCDM methods rank alternatives but do not benchmark them (Alessio and Nemery 2013). Therefore, multi-criteria sorting methods have been developed: AHPSort (Ishizaka, Pearman, and Nemery 2012), FlowSort (Nemery and Lamboray 2008), Electre-Tri (Mousseau, Slowinski, and Zielniewicz 2000), ELECTRE-Sort (Ishizaka and Nemery 2014), MACBETHSort (Ishizaka and Gordon 2017) and GAIASort (Nemery et al. 2012). Their aim is to classify alternatives in predefined ordered classes. AHPSort has been adapted from AHP and retains all its advantages. It enables evaluating only two elements at a time, which provides more precise information (Millet 1997). The problem is structured in a hierarchy, which makes the problem easier to visualise, solve and explain. The decision quality is also enhanced, due to the consistency check and sensitivity analysis embedded in the AHPSort-AHP method. AHPSort has been further improved to be applied to major problems (Miccoli and Ishizaka 2017) and group decisions (López and Ishizaka 2017a). Although AHPSort has been useful, a unique hierarchy is confusing when criteria to maximise and to minimise are mixed. Therefore, in this paper, we propose a Cost-Benefit AHPSort, where cost and benefit criteria are separated into two distinct hierarchies. The classification will then be done in a grid and feedback to providers will be given. This will help them to gain a better understanding of their performance and therefore to make more accurate targeted actions. The new method is illustrated in a real case study of provider performance analysis for an aerospace manufacturing company, where two consecutive evaluations of offshore providers at a one-year interval are carried out.

The rest of the paper contains a literature review of performance analyses of outsourcing processes in Section 2. Section 3 describes the Cost-benefit AHPSort. Section 4 presents the case study and Section 5 concludes the paper.

\section{Literature review of performance analyses of outsourcing processes}

Offshore outsourcing strategy has become widely adopted by both manufacturing and service firms over the last decades. This refers to the transference of a concrete process or value chain activities from a client firm to one or more independent providers operating in a foreign country.

According to Mihalache and Mihalache (2015), the main aim of offshore outsourcing processes is to optimise the client firm value chain by performing specific tasks in locations that present specific advantages in terms of competencies, labour availability or cost structures. Nevertheless, when the client firm outsource a significant part of its processes to offshore providers, it can create additional risks and unrecognised threats often arise (Herath and Kishore 2009; Nakatsu and lacovou 2009). In this manner, Steven, Dong, and Corsi (2014) highlight that geographic and cultural distances between both sides might lead to information asymmetry which will negatively impact on quality recalls. As results of offshore outsourcing risks, the Boing 787 incorporated faulty lithium-ion batteries causing fires and thus a grounded fleet (Denning 2013). Hence, the business profitability and market position 
of the client firm could be severely damaged. It is no wonder that today some companies are even considering the possibility of bringing their offshore outsourincing activities back home (Barbieri et al. 2018; Di Mauro et al. 2018; Brandon-Jones et al. 2017). In this way, it has been empirically analysed whether offshoring and reshoring strategies have provided better or worse cost performance, cost accouting capabilities and operational performance (Stentoft et al. 2018). In order to achieve success in outsourcing, client firms must invest in effective performance measurement (Whitaker, Kumar, and Krishnan 2018).

Undesired outcomes in offshore outsourcing would be avoided through a continuous feedback and a proper performance evaluation of providers, which encourage the stability in offshore outsourcing relationships (Manning, Lewin, and Schuerch 2011). A successful offshoring relationship lies in a good co-specialisation, effective coordination efforts and collaboration between both the client firm and the offshore provider (Mukherjee, Gaur, and Datta 2013). A client outcome control has shown an improvement ofor has even substuituted the effect of vendor outcome control (Zheng et al. 2018). In order to attain this, the development of measurable specifications is required (Ellram, Tate, and Billington 2008; Rottman and Lacity 2006). In spite of this, few research efforts have been carried out to support the performance analysis of providers once the process has already been outsourced.

Khan et al. (2003) presented a benefit and risk framework of offshore outsourcing process thatdoes not incorporate specific performance measures. Wu (2010) carried out a stochastic DEA model to estimate the efficiency of offshore outsourcing providers and rank them. Sivapornpunlerd and Setamanit (2014) applied AHP in a case study to evaluate the providers' performance of an offshore enterprise in Thailand. Sivapornpunlerd and Setamanit (2014) developed an AHP-based provider performance evaluation system . The same technique has been used for measuring the green supply chain performance (Dey and Cheffi 2013). AHP has also been combined with fuzzy logic and fuzzy TOPSIS to measure the performance of advanced manufacturing systems (Mohammadzadeh et al. 2011). Bentes et al. (2012) integrated AHP and Balance Scorecard (BSC) to measure the organisational performance of a telecom company. For their part, Modak, Pathak, and Ghosh (2017) combined FAHP and BSC to assess organisational performance in outsourcing decisions. In this vein, Yadav et al. (2018) have recently proposed a hybrid BWM-ELECTRE method to evaluate effective offshore outsourcing adoption in client firms. In spite of the development of strategies which facilitate low cost and high value contracts in offshore outsourcing having been reported as a critical challenge (Weerakkody and Irani 2010), no method has been identified to evaluate the performance of an offshore provider considering costs and benefits in multicriteria sorting methods.

The performance of offshore providers is complicated to determine because of the fact that multiple criteria must be considered, and these are often based on a subjective metrics. Moreover, some criteria would need to be maximised (benefit criteria) and some to be minimised (cost criteria). These issues together with scant information available in outsourced processes largely exceed the managers' cognitive ability to intuitively assess offshore provider performance. Accordingly, this article proposes a new Cost-Benefit sorting method to evaluate offshore outsourcing providers. This is 
presented in Section 3 and applied in a real case study described in Section 4.

\section{The proposed method}

Generally, decisions are based on benefits (positive) versus costs (negative). Nonetheless, benefits and costs are often difficult to express in monetary terms, especially when intangible benefits and costs are to be evaluated. Therefore, AHP has been used for benefit/cost analysis (Azis 1990; Ishizaka and Labib 2011). Two hierarchies are constructed, one for costs and one for benefits. The priorities derived are expressed on a derived ratio scale. The main criticism of benefit/cost analysis with AHP is that different hierarchies produce priorities in different relative derived ratio scales, and these are generally not commensurate. It is therefore not possible to calculate a meaningful cost/benefit ratio (Wijnmalen 2007). The cost-benefit AHPSort method reuses the idea of having two separate hierarchies but for a sorting problem. Yet, it eliminates the problem of two different relative ratio scales as each alternative is compared only with the benchmarks. As the benchmarks are the same for all alternatives, the relative magnitude is the same for all alternatives. Furthermore, a ratio is not calculated but results are analysed in a two-dimensional grid.

This section describes the Cost-Benefit AHPSort method, which is based on nine steps and three main phases: problem definition, evaluations and assignment to classes.

\section{A) Problem definition}

1) Before being solved, a problem needs to be clearly defined, otherwise we may not solve the correct problem. For this task, the goal of the problem needs to be defined along with the benefit criteria $c_{b}, \mathrm{~b}=1, \ldots, m$, cost criteria $c_{c}, \mathrm{c}=1, \ldots, \mathrm{o}$ and alternatives $a_{k} \mathrm{k}=1, \ldots, \mathrm{I}$ of the problem. This is the first important difference from the previous methods listed in Section 2. The criteria to be minimised (cost criteria) and the criteria to be maximised (benefit criteria) are listed in two different groups.

2) As it is a sorting problem, the number $n$ of classes $C_{i}, i=1, \ldots, n$ with its label (e.g., excellent, good, average, bad) needs to be defined. . The classes are ordered from the best to the worst.

3) The classes labelled in 2) need to be defined. This can be automatically, e.g., with a Kneighbour algorithm as in (Lolli, Ishizaka, and Gamberini 2014), or through decision makers, if they have some information; for example, based on their experience. The most precise way to define classes by a decision maker is to provide the minimum requirement to belong to a class. This is done by defining local limiting profiles $l p_{i b}$ and $I p_{i c}$ for each class. This indicates the minimum performance needed in each benefit and cost criterion to belong to a class $C_{i}$, We need $(m+o) \cdot n-1$ limiting profiles to define each class. It is to be noted that central profiles, as in the AHPSort standard, can also be used. 


\section{B) Evaluations}

4) The evaluation of criteria is done in a pairwise comparison matrix. It has been proven that pairwise comparisons are more precise than direct rating (Millet 1997; Por and Budescu 2017). The benefit criteria $c_{b}$ and the cost criteria $c_{c}$ are evaluated separately; therefore, two comparisons matrices are needed. There are different ways to derive the criteria weights $w_{b}$ and $w_{c}$ from the comparisons matrices (Ishizaka and Lusti 2006). The most popular is the eigenvalue method of the AHP (Saaty 1977).

$\mathbf{A} \cdot \mathbf{p}=\lambda \cdot \mathbf{p}$

where $A$ is the comparison matrix

$p$ is the priorities/weight vector

$\lambda$ is the maximal eigenvalue

5) In this step, the alternatives will be prioritised in terms of how beneficial they are. They are benchmarked against the limiting profiles $/ p_{b i}$ defined in step 1$)$. One alternative $a_{k}$ is compared pairwise with each limiting profile $I p_{b i}$ and for each benefit criterion. These evaluations are entered into the benefit comparison matrix, one for each criterion. From this matrix, we derive the local benefit priority $p_{b k}$ for the alternative $a_{k}$ with the eigenvalue method (2). We also derive the local benefit priority $p_{b i}$ for the limiting profiles $I p_{b i}$, with the same method (2). A comparison of the local benefit priority of the limiting profiles $l p_{b i}$, and of the alternative $a_{k}$ will be used for the classification in step 7.

6) In this step, the alternatives will be prioritised in terms of how costly they are. This means that a higher score reflects a higher cost. As in 5), they are benchmarked, but this time against the limiting profiles $I p_{c i}$ defined in step 1$)$. One alternative $a_{k}$ is compared pairwise with each limiting profile $I p_{c i}$ and for each cost criterion. These evaluations are entered into the cost comparison matrix, one for each criterion. From this matrix, we derive the local cost priority $p_{c k}$ for the alternative $a_{k}$ with the eigenvalue method (2). We also derive the local cost priority $p_{c i}$ for the limiting profiles $I p_{c i}$, with the same method (2). A comparison of the local cost priority of the limiting profiles $I p_{c i}$ and of the alternative $a_{k}$ will be used for the classification in step 7 .

\section{C) Assignment to classes}

7) In the two previous steps, we have calculated the local priorities. In this step, we wish to know the global priority, i.e., as regards all the criteria. For this purpose, the weighted local priorities are aggregated, which provides a global cost priority $p_{c k}(3)$ and a global benefit priority $p_{b k}$ for the alternative $k(4)$, a global cost priority $I p_{c i}$ for the limiting profile (5) and a global benefit priority $I p_{b i}$ for the limiting profile (6). 
$p_{c k}=\sum_{c=1}^{o} p_{c k} \cdot w_{c}$

$p_{b k}=\sum_{b=1}^{m} p_{b k} \cdot w_{b}$

$I p_{c i}=\sum_{c=1}^{o} p_{c i} \cdot w_{c}$

$I p_{b i}=\sum_{b=1}^{m} p_{b i} \cdot w_{b}$

The comparison of $p_{c k}$ with $I p_{c i}$ is used to assign the alternative $a_{k}$ to a class $C_{c i}$ according to its cost criteria. This step does not exist in ranking techniques, where only the score of the global priority matters. The comparison of $p_{b k}$ with $l p_{b i}$ is used to assign the alternative $a_{k}$ to a class $C_{b i}$ according to its benefit criteria. The next paragraph describes the assignment procedure for the benefit criteria. The assignment for the cost criteria follows exactly the same procedure. If limiting profiles have been defined, the alternative $a_{k}$ is assigned to the class $C_{c i}$ that has the $l p_{i}$ just below the global priority $p_{k}$ (Figure 1 ).

$$
\begin{array}{ll}
p_{b k} \geq l p_{b 1} & \Rightarrow a_{k} \in C_{c 1} \\
l p_{b 2} \leq p_{b k}<I p_{b 1} & \Rightarrow a_{k} \in C_{c 2} \\
\cdots & \Rightarrow a_{k} \in C_{c n}
\end{array}
$$

\section{Insert Figure 1}

Figure 1. Sorting with limiting profiles

8) The final classification is given by the assignment on the cost and benefit criteria. If both assignments are identical $C_{c l}=C_{b i}$, then $a_{k}$ is assigned unanimously to $C_{i}$. If $C_{c i} \neq C_{b j}$, then $a_{k}$ can belong to several classes: the class is an interval covering the class from $C_{i}$ to $C_{j}$. The results can be visualised in a 2-dimensional decision-grid, where the dimensions are the cost and benefit global priorities. This decision grid facilitates the visual management of the decision.

9) As this process is aimed to classify only one alternative at a time, the process 5) to 8) needs to be repeated for each alternative to be classified.

\section{Evaluation of offshore outsourcing providers: a case study.}


AHPSort has been adopted for supporting an offshore outsourcing decision making in a European aerospace manufacturing industry. This industry revenues reached USD 674.4 billion in 2016, where the European sector revenue growth $(8.2 \%)$ is higher than the US sector (1.4\%) (Lineberger and Hussain 2017). European aerospace manufacturing SC is structured around tiers. At the top of the pyramid, Original Equipment Manufacturer (OEM) aims at assembling final aircrafts to order and at the same time building large aero structures. First-tier providers build to order components and subcomponents. Second-tier providers manufacture instruments, parts and devices and/or provide multiple engineering services.

According to (Chirulescu 2017), managing an increasingly complex global SC is one of the most important challenges that European aerospace manufacturing currently faces. Over the last decades, the volume of offshored outsourcing activities has augmented increasingly more due mainly to cost pressure and the need to shorten development time, thereby allowing the client firm to focus on its core competencies and specific skills. In fact, a report reflected a strong tendency to outsource offshore in the European aerospace manufacturing sector by detecting mismatches between the growth of the production and value-added (Ecorys 2009). In addition, the engineering service outsourcing market demand in aerospace manufacturing sector was estimated at around USD 4.71 billion in 2012 (GVR 2014), forecasting a very high growth in the period 2012-2020.

Offshore outsourcing is not exempt from significant challenges in the aerospace manufacturing sector. The performance of providers is critical for the client firm (WCIR 2013). Hence, a European aerospace manufacturing firm was finally chosen to illustrate the Cost-Benefit AHPSort method. The company studied operates in the first-level of its SC providing a great variety of aerospace components to the two most important aircraft manufacturers worldwide. It has diverse plants in Europe, at the same time as it has outsourced some of its processes to specialised providers outside abroad.

To collect the data required in the case study, we conducted two semi-structured interviews with the operations manager, who is also the decision maker. The problem was described in detail during the first interview, which included the goal, classes, and the cost and benefit criteria definition. Subsequently, the operations manager compared the cost and benefit criteria in terms of importance within their respective hierarchies. At the beginning of the second interview, the operations manager revised the hierarchies and defined the limiting profiles for each criterion. In addition, the decision maker individually assessed the providers with pairwise comparisons for each criterion. The widely accepted nine-point scale suggested by Saaty (1977) was used in all the evaluations. The results were sent to offshore providers to guide them in developing improvement actions. After completing a transitional period, the operations manager carried out a third interview to again assess the providers' performance. The operations manager was also contacted via telephone and answered questions that had been overlooked during the interviews.

4.1 Problem definition 
One of the client firm's offshored outsourcing processes was the edge finishing of metallic pieces and equipment. Currently, they have four providers:

- Provider 1 carries out the manual edge finishing of metallic pieces and equipment in Asia.

- Provider 2 also carries out the manual edge finishing of metallic pieces and equipment in Europe.

- Provider 3 carries out the automatic edge finishing of metallic pieces and equipment in Europe.

- Provider 4 carries out the manual edge finishing of metallic pieces and equipment in South America.

These providers shape metallic pieces and assemble simple mechanisms. They will be subsequently assembled into more complex components by the client firm. The aim of this research was to measure the performance of the existing providers. In doing so, the decision maker defined two hierarchies. These are described below.

\subsubsection{Cost criteria}

One of the hierarchies of the problem is made up of cost criteria, which the client company seeks to minimise. From a cost-benefit analysis point of view, cost criteria are those that require direct or indirect spending from the client firm. The following cost criteria were identified:

- Logistic cost, which includes the charges derived from the transport of the finished metallic pieces and equipment by any mode between the client company and the provider, warehousing, transport packaging, inventory carrying, administration and other indirect cost (Engblom et al. 2012). The geographical distance itself between the client firm and the offshore providers gives rise to a high logistic cost, although this is also conditioned by many factors such as the mode of transport, insurance, the transport infrastructure of each offshore location and so on. This cost is even encouraging some client firms to relocate and backshore activities that had been offshored (Di Mauro et al. 2018). Because of offshore providers being geographically located in distant countries, the operation managers aimed at minimising logistic cost.

- Inventory cost arises from holding metallic pieces and equipment in stock once the shipment is received by the client firm. According to (Lee and Billington 1992), its assessment should include the costs of capital, warehousing, storage, obsolescence and the cost of reworking the existing inventory to meet engineering changes. This criterion is strongly and directly related to the purchase order rigidity, fixed lot size, container-size minimum order, order frequency and lead-time. Indeed, the longer lead-times (as usual in offshore outsourcing) implies higher inventory levels to meet customers' expectations and thus raise their associated costs (Kumar and Wilson 2009). This matter is even pointed out as a driver in reshoring and insourcing decisions (Fratocchi et al. 2016; Brandon-Jones et al. 2017). In fact, it has become a challenge to maintain inventory to a minimum when 
complex pieces and equipment have been outsourced to distant regions, as in this case study.

- Impact on the assembly/adherence time; that is, the effect of the time delivery of outsourced metallic pieces and equipment on the assembly/adherence time. This operation performs the assembly of individual parts, subassemblies and substances into uppermost components or final product assemblies of a given quantity and complexity in a given period of time (Choi, Chan, and Yuen 2002). Offshore outsourcing has been shown to lead to operational risks derived from the complexity of operations, cultural differences, communication constraints and the geographic distance between the client firm and the outsourced providers (Herath and Kishore 2009), and to lengthen the development cycle time. This fact has been also aggravated by the recent adoption of slow-steaming ocean freight in the shipping industry (Tate et al. 2014), which slows down the velocity of transoceanic shipments. In this way, major delays registered in the client firm's receptions from an offshore provider in turn resulted in delays in delivery to the costumer. In order to minimise this issue, this criterion was also added into the cost hierarchy.

- Non-quality cost, also unknown as cost of poor quality, comprises those charges that would not be incurred in the case of the whole products and processes being perfect (Isaksson 2005). Problems of quality in outsourced products or services has been viewed as a disadvantage of offshore outsourcing (Dolgui and Proth 2013) and therefore a driver for reshoring (Fratocchi et al. 2016; Barbieri et al. 2018; Hartman et al. 2017). A quality criterion is normally considered in the selection of offshore outsourcing providers (Wadhwa and Ravindran 2007; Kaur, Singh, and Majumdar 2018; Kahraman, Beskese, and Kaya 2010), but this is not enough to avoid some quality problems. When a faulty piece or equipment is received, the client firm checks it and generates a discrepancies report. The provider then must send a further piece that fulfils the initial requirements agreed upon as soon as possible to the client firm, causing delays in assembly operations and production. All charges derived from receiving faulty metallic pieces or equipment represents a non-quality cost that the client firm seeks to minimise.

- Hourly rate paid by the client firm for receiving the outsourced metallic pieces and equipment in good conditions from an offshore provider. This must be carefully estimated by addressing direct and indirect costs (Smite, Britto, and van Solingen 2017; Marion, Thevenot, and Simpson 2007), as well as hidden costs derived from interaction distance, and cultural differences or inflexibility (Stringfellow, Teagarden, and Nie 2008; Lowson 2002). Regarding getting huge cost savings from its offshore outsourcing strategy, the operation manager emphasised the need to minimise this.

\subsubsection{Benefit criteria}

The second hierarchy brings together the benefit criteria that the client firm pursues to maximise. 
These criteria aim to attain quantitative or qualitative benefits for the client company. Five criteria were defined:

- Work environment improvements in the client firm, since the process generating hazardous wastes at the workplace is outsourced.Offshore providers must also guarantee the safety and health condition of their employees to continue performing the outsourced process. There is a growing concern to manage companies and their operational linkages in a more sustainable way. This matter implies guiding operations towards a compliance with specific environmental, economic and social objectives that represent the triple bottom line (Walker et al. 2014), offshore outsourcing operations playing a vital role to attain them (Resta et al. 2017; Martínez-Jurado and Moyano-Fuentes 2014). One of the social objectives is the improvement of safety and health conditions at the workplace (Giannakis and Papadopoulos 2016), which the operations manager pursues to maximise

- Specialisation improvements or co-specialisation results in greater value-added of the final product delivered to the final client. As the outsourced process is the core business of the overseas providers, this allows the client firm to focus primarily on its core business processes and thus to rethink its business model (Lahiri and Kedia 2011). This is in line with the fact that co-specialisation fosters new generated knowledge (Mukherjee, Gaur, and Datta 2013) and improves client firms' innovation capabilities (Nieto and Rodríguez 2011). If the greater value-added were finally obtained and this was perceived by the final clients, this would lead to increasing the total revenue in the client firm. Hence, the operation manager aims at maximising specialised improvements.

- Increases in cash flow are achieved by driving down unit costs (Stentoft et al. 2018). In the same vein, client firms may reach a higher financial flexibility through the sale of disused assets as a result of outsourcing a process (Dolgui and Proth 2013). The client firm has achieved the enhancing of its cash flow level thanks to lower process costs and material handling costs recorded because the edge finishing of metallic pieces and the equipment process was outsourced abroad. The operation manager wants to maximise this increase in cash-flow as much as possible.

- Reduction of lead-time of the client firm, which is equal to the time that the client firm would need if it had to perform the outsourced process. This term encompasses queue time, process time, the provider's lead-time, move time, wait time and setup time (Tersine 1993). However, Stentoft et al. (2018) revealed firms that have moved manufacturing abroad achieved a lower performance level on lead time than those firms which have maintained their manufacturing at home. Hence, additional efforts will be required to maximise the reduction of lead time. This reduction depends on the completion method applied by providers, although it would be even higher if the lot size or inventory in safety stocks were smaller, or emerging manufacturing technologies were implemented (Dietrich and Cudney 2011; Lin, Chen, and Hsiao 2011; Yang and Pan 2004), among other actions. Since the 
client firm follows a Just-in-Time purchasing system, shortening its lead-time is considered a primary criterion.

- Better cooperation in the global Supply Chain (SC) thanks to the introduction of new specialised agents operating in different continents. The expansion and strength of relational ties beyond the client firm's frontiers generated by offshore outsourcing may bring improvements in exportation performance and international competitiveness (Di Gregorio, Musteen, and Thomas 2009; Bertrand 2011). In addition, certain resilience capabilities in the SC would be even reinforced (López and Ishizaka, 2017). For these reasons, the client company seeks to maximise this criterion.

\subsubsection{Limiting profile between classes}

Three classes, low, medium and high performance, were defined. The ultimate goal was to classify each offshore provider. Therefore, the decision maker also defined the limiting profiles of each class. These are shown in Table 1. For example, the limiting profile low-medium on logistic cost indicates that when this amount is greater than $15 \%$ of the total value of the outsourced metallic pieces and equipment, the provider moves from class low cost to class medium cost.

Table 1. Limiting profiles of the criteria

Insert Table 1

\subsection{Evaluation of offshore outsourcing providers}

According to the methodology applied in this study, the decision maker had to provide several evaluations. The procedures and findings are detailed in the following subsections.

\subsubsection{Weight of the criteria}

In the first interview, the decision maker separately determined the importance of the benefit criteria and the cost criteria. In doing so, he carried out paired comparisons of cost criteria and benefit criteria in the nine-point scale proposed in (Saaty 1977). We subsequently introduced the extracted judgment matrices in Expert Choice for calculating the priorities with the eigenvalue method (2).

The priorities of cost criteria are depicted in Table 2. Non-quality cost reached the highest global weight of 0.555 . Its importance was from 2 to 18.5 times greater than the other criteria. Inventory cost was ranked in second place with a global weight of 0.275 . These two costs criteria add up to $83 \%$ of the total global weight and therefore offshore providers should have minimised to a greater extent those two cost criteria to provide a good performance to the client firm. Otherwise, offshore providers probably need to improve or even might need to be replaced. 
Table 3 shows the priorities of the benefit criteria. The reduction of the lead-time achieved the highest global weight of 0.459 . Its importance was from 1.4 to 17 times greater than the other criteria. Cash flow and specialisation were considered as the second and third most important benefit criteria, with a global weight of 0.328 and 0.151 respectively. The importance of these three benefit criteria amounted to $93.8 \%$ of the total global weight. The offshore providers should have thus maximised them to a larger extent to provide a good performance. If one of the providers got a negative evaluation in those benefit criteria, it would probably need to be replaced.

Table 3. Global weights of benefit criteria

Insert Table 3

\subsubsection{First evaluation}

The decision maker compared pairwise each offshore provider with the limiting profile in each criterion during the second interview. The appendix shows an extract of the questionnaire answered. We computed the priorities of each provider and their limiting profiles with Expert Choice. As this software is not primarily designed for sorting decisions, it requires a file for each provider (López and Ishizaka 2017a; Ishizaka, Pearman, and Nemery 2012). Given that we had two hierarchies, we created eight files. The results according to the cost and benefit criteria are listed in Tables 4 and 5, respectively. These tables are used for the assignment of the providers. From the cost criteria point of view, provider 3 achieved a lower value $\left(p_{c 3}=0.090\right)$ compared to the limiting profile low-medium score $\left(\mathrm{I}_{\mathrm{c} 3,1}=0.289\right)$. Hence, it was assigned into class 'Low cost'. This means that provider 3 generates low cost to the client firm when that offshore firm produces outsourced metallic pieces and equipment. On the contrary, provider 4 reached a higher score $\left(\mathrm{p}_{\mathrm{c} 4}\right.$ $=0.728)$ compared to the limiting profile medium-high value $\left(\mid p_{\mathrm{c} 4,2}=0.185\right)$ for the cost criteria. The client company thus regarded it as a provider that generates high costs. Both provider 1 and 2 were classified in intermediate positions, and these were therefore assigned to the class 'Medium cost'.

Table 4. Global priorities for providers and limiting profiles according to cost criteria Insert Table 4

Concerning the benefit criteria, provider 3 obtained a higher value $\left(p_{b 3}=0.751\right)$ compared to the limiting profile medium-high score $\left(\mathrm{I}_{\mathrm{b} 3,2}=0.164\right)$ for these criteria and was therefore assigned to class 'High benefit'. Accordingly, this alternative provides the client firm with high benefits when this offshore company makes outsourced metallic pieces and equipment. Providers $1\left(p_{b 1}=0.076\right)$ and $4\left(p_{b 4}=0.069\right)$ were assigned to the class 'Low benefit' since they achieved lower scores compared to their respective limiting profile low-medium values $\left(\operatorname{lp}_{\mathrm{b} 1,1}=0.321\right)$ and $\left(p_{\mathrm{b} 4,1}=0.324\right)$ 
for the benefit criteria. Nevertheless, provider 2 reached a value between the limiting profile lowmedium value and limiting profile medium-high value. This alternative thus provides a medium benefit to the client firm.

Table 5. Global priorities for providers and limiting profiles according to benefit criteria in the first evaluation Insert Table 5

Results in cost criteria and benefit criteria were not considered in isolation since this might lead to wrong decisions. Hence, we developed a cost-benefit analysis to individually evaluate each offshore outsourcing provider of the client firm. This analysis resulted from the joint understanding of the global priorities for the providers and the limiting profiles according to the cost and benefit criteria listed in Tables 4 and 5, respectively. Table 6 presents the local priorities for providers and the limiting profiles in each one of the criteria. These results will help the client firm to develop a more accurate diagnosis of the four providers' performance in the past, as well as making a concrete decision concerning each provider.

In order to facilitate an understanding of the final decision, Figure 2 represents the case of provider 1. Looking at this figure, it can be observed that this provider led to a medium cost to the client firm. As Table 6 shows, this is due to provider 1 generating high logistic and inventory costs, as well as a high assembly/adherence time for the client firm. These cost criteria are offset by a medium non-quality cost and a low hourly rate, and thus this outsourcing was performed with a medium cost. In addition, Figure 3 depicts provider 1 as providing a low benefit because of a low increase in cash flow, a low improvement in the work environment at provider 1's workplace, as well as a low reduction of the client firm's lead-time. In the light of these findings, it was determined that provider 1 needed to be replaced.

\section{Insert Figure 2}

Figure 2. Evaluation of provider 1 in the first evaluation

Focusing our attention on the results of provider 2, a medium cost and medium benefits can be seen, situating it exactly in the middle of the evaluation grid. Accordingly, this provider will need to improve its performance in some criteria. On the one hand, the impact of outsourcing metallic pieces and equipment to provider 2 was low, although the rest of the cost criteria generated a medium cost. As inventory, cost and non-quality cost were considered the most important cost criteria for the client firm, provider 2 ought to mainly focus its efforts on reducing them. This provider would thus provide the client firm with a better performance in a more effective way. On the other hand, provider 2 received either low scores or medium scores in all the benefit criteria. In light of this result, the provider should carry out several actions. It ought to encourage the establishment 
of further commercial agreements between its partners and the client firm. It should also allow outsourcing additional functionalities to improve health conditions at the client firm's workplace. In addition, provider 2 offered a medium reduction of the client firm's lead-time, this benefit criteria being the most important. Hence, provider 2 ought to additionally make efforts in this issue. For example, it could implement an automatic completion method and/or look for alternative transportation routes to shorten the delivery time, and thus the client firm might reduce its lot size. If these improvements are achieved, the client firm should carry on outsourcing metallic pieces and equipment to provider 2 .

The outsourcing of metallic pieces and equipment to provider 3 led to a low cost and a high benefit to the client firm. Indeed, this caused a low cost in 4 out of the 5 criteria considered. Furthermore, provider 3 offered high benefits thanks to its high performance in specialisation, cash flow and lead-time. Hence, it was concluded that this offshore provider provides a good performance.

Finally, provider 4 generated a high cost to the client firm. More specifically, this offshore provider generated a high cost in 4 out of the 5 criteria, only being low for its hourly rate. That is just the opposite performance of provider 3, where the unique high cost criterion was its hourly rate. Provider 4 also presented a bad performance from the benefit criteria point of view. In this way, this offshore firm brought low improvements in cash flow, lead-time and the work environment. These under-performances were not offset by a medium benefit in the criteria specialisation and a better cooperation in the global Supply Chain. Therefore, it was determined that provider 4 needed to be replaced.

Table 6. Local priorities for providers and limiting profiles according to each criterion in the first evaluation Insert Table 6

\subsubsection{Second evaluation}

The first evaluation allowed the client firm to develop a benchmarking of its offshore providers' performances. These results were individually shared with these providers so as to more accurately undertake targeted action improvements. Once the transitional period was completed, the decision maker carried out a second evaluation. The procedure was the same as in the first evaluation. Tables 7 and 8 show the global performance reached by offshore providers according to the cost and benefit criteria, respectively, whilst Table 9 gives a more detailed breakdown of the offshore providers' performance from each criterion perspective.

Table 7. Global priorities for providers and limiting profiles according to cost criteria in the second

$$
\begin{gathered}
\text { evaluation } \\
\text { Insert Table } 7
\end{gathered}
$$

Table 8. Global priorities for providers and limiting profiles according to benefit criteria in the second 
evaluation

Insert Table 8

Table 9. Local priorities for providers and limiting profiles according to each criterion in the second evaluation

Insert Table 9

Provider 1 achieved a lower value $\left(\mathrm{p}_{\mathrm{c} 1}=0.154\right)$ compared to the limiting profile low-medium score $\left(I p_{c 1,1}=0.247\right)$, and therefore was reclassified into the class "low cost". This was made possible through the development of certain improvement actions. In this way, it was agreed to adopt a vendor inventory management system. This implied that provider 1 takes over maintaining the outsourced pieces and components on consignment until the time these arrive at the client firm's warehouse. This action enabled a moderate reduction of the inventory cost as well as a small decrease of the logistic cost. Indeed, Table 9 reveals that provider 1 generated a medium inventory cost for the client firm in the second evaluation. This provider also agreed upon maintaining a buffer of finished pieces and components so as to minimise delays and delivery time. Provider 1 therefore managed to cause a low impact on the assembly/adherence time of the client firm in the second evaluation. Furthermore, this provider minimised faulty pieces or equipment submitted on account of automatizing the statistic control of its process. This allowed the generating of a low non-quality cost for the client firm in the second evaluation. These actions involved a rise of the hourly rate paid by the client firm, although, as Figure 9 notes, this continued to be low. Focusing our attention on the benefit criteria, this provider has also generated higher benefits in the second evaluation. More specifically, it attained a value $\left(p_{b 1}=0.187\right)$ between the limiting profiles low-medium score $\left(\mid p_{b 1,1}=0.123\right)$ and medium-high score $\left(\mid p_{b 1,2}=0.691\right)$ and was therefore assigned to the class 'Medium benefits'. The agreement on consignment material also caused provider 1 to go from generating a low benefit in the cash flow criterion in the first evaluation to a medium benefit in the second evaluation. Considering these advances, it was determined that provider 1 had made important and effective efforts to currently provide a good performance.

In the case of provider 2, enough enhancements in both the cost and benefit criteria to significantly change its ratings were not reported. This provider also accepted to maintain the outsourced pieces and components on consignment during transportation in return for a slight rise in the hourly rate received. As a result, the client firm could drive down its inventory levels in safety stock, and hence achieved a lower inventory cost than in the first evaluation. Notwithstanding, this reduction was not enough to reach the class "low inventory cost". Provider 2 had also achieved a better performance in the criteria cash flow and reduction of lead-time, although it was again classified between the limiting profiles low-medium and medium-high. In spite of these improvements, provider 2 continued to generate "medium cost" and "medium benefits" for the client firm and, in consequence, further efforts are requested to provide a good performance.

Provider 3 already got a good performance in the first evaluation. Yet, these findings did not hold 
up to the progress made with additional action improvements. Both parties agreed on introducing a common measurement analysis system that allowed aligning their quality criteria. By doing so, provider 3 led to a lower cost $\left(p_{\mathrm{c} 3}=0.077\right)$ compared to the limiting profile low-medium score $\left(\mathrm{l}_{\mathrm{c} 3,1}\right.$ $=0.303$ ) or low cost. Likewise, healthier conditions at the client firm's workplace were noted because of outsourcing additional functionalities to provider 3 . The second evaluation showed that this provider led to a higher benefit $\left(\mathrm{p}_{\mathrm{b} 3}=0.764\right)$ than the limiting profile medium-high score $\left(\mathrm{l}_{\mathrm{b} 3,2}=\right.$ 0.163 ) or high benefit. The results therefore highlight that this provider 3 sustained its high level of performance.

On the other side of the coin, provider 4 made some progress although this was not enough to improve its performance. From the cost criteria perspective, the logistic cost has changed into the class "medium cost". This reduction derives from starting up making drop shipments through a new logistic operator. This provider also accepted maintaining the outsourced material on consignment until the client firm received it, which moderately minimised the inventory cost of the client firm. Moreover, this action enabled attaining a medium level of performance in both the cash flow criterion and the reduction of lead-time criterion. Provider 4 has also gone from generating a high impact on the client firm's assembly/adherence time to a low impact. This was due to this provider agreeing to maintain a buffer of the finished pieces and components supplied in return for a moderate increase in the hourly rate charged. In spite of these efforts, provider 4 again achieved a higher cost criteria score $\left(p_{c 4}=0.498\right)$ compared to the limiting profile medium-high value $\left(\mathrm{l}_{\mathrm{c} 4,2}\right.$ $=0.417$ ), at the same time that it went from the "low benefit" class to the "medium benefits" class. Consequently, it was recommended that provider 4 be replaced.

\section{Conclusions}

An adapted Cost-Benefit AHPSort was developed to facilitate the performance evaluation of offshore providers. This method provides the benchmarking of provider performance in the outsourced process based on isolated targeted cost and benefit criteria. The results are subsequently represented in a grid that facilitates the decision making in each case.

The usefulness and applicability of Cost-Benefit AHPSort have been proven through evaluations in two different periods of offshore providers in the aerospace manufacturing sector. Since managers pursue minimising cost criteria and maximising benefit criteria in the performance evaluation, these criteria must not be considered in the same way. Therefore, the performance measures were broken down into cost criteria and benefit criteria, which makes the problem more manageable and realistic. Thus, managers will be able to be aware of the negative effect of cost criteria at the same time as the positive effect of benefit criteria in a unique benchmarking of providers. Furthermore, this was set at three performance levels, being clearly defined by the limiting profile on each criterion. The findings contributed to a better understanding of the decision maker about the performance offered by the providers in the outsourced process, both at the global level and locally within each criterion. The decision quality was hence enhanced at the same time 
as valuable improvement recommendations to offshore providers were given. They could translate this feedback into coordinated actions that significantly improved their performance, which were post-evaluated again with Cost-Benefit AHPSort.

Other benefits of choosing AHPSort in the selection of offshore service providers are also highlighted from this study. The structured methodology reduces the time and efforts required by managers in the performance evaluation of offshore providers. Furthermore, AHPSort is not only about telling if a provider meets or fails to meet the desired performance. It has also the advantage of providing an exact position as regards the targets in a decision grid. This strong point in the model can visually help the managers to set their next improvement targets. Looking to future offshore outsourcing decisions, benchmarking would be an excellent mechanism to perform further evaluations, since the whole decision-making process has been already formulated. This would be easily adapted if further elements (i.e., criteria, classes, etc.) are added to the current model.

Our research also provides new advances in the offshore outsourcing literature because it is the first time that a Cost-Benefit method has been proposed to evaluate offshore provider performance. In addition, it incorporates the definition of limiting profiles and classes to make decisions that are more accurate and provide feedback to offshore providers. Additionally, the proposed multi-criteria decision sorting method presents certain strengths in comparison to previous methods. CostBenefit AHPSort solves the problem of the incommensurate ratio scaled derived from the benefit and cost comparison matrices by having fixed benchmarks. This allows the minimisation of the cost criteria and the maximisation of the benefit criteria in separated hierarchies, reducing the pairwise comparisons needed in the evaluation phase.

Despite the progress achieved in this article, new issues should be addressed in future studies. Cost-Benefit AHPSort could incorporate fuzzy approaches to handle the impreciseness and vagueness of the evaluation process. Moreover, the proposed method can be easily adopted to track other offshore outsourcing challenges. In this way, it would be combined with other techniques. Finally, since this research was developed in a concrete case, when applying this model to other industries analysts must be aware that other costs (e.g., human resources or talent cost in offshoring design and software development services) and benefits (e.g., strategic flexibility and productivity) could be considered. 


\section{REFERENCES}

Asadabadi, Mehdi Rajabi. 2017. "A Customer Based Provider Selection Process That Combines Quality Function Deployment, the Analytic Network Process and a Markov Chain." European Journal of Operational Research 263 (3): 1049-1062. doi:10.1016/j.ejor.2017.06.006.

Azis, Iwan J. 1990. "Analytic Hierarchy Process in the Benefit-Cost Framework: A PostEvaluation of the Trans-Sumatra Highway Project." European Journal of Operational Research 48 (1): 38-48. doi:10.1016/0377-2217(90)90059-K.

Barbieri, Paolo, Francesco Ciabuschi, Luciano Fratocchi, and Matteo Vignoli. 2018. "What Do We Know about Manufacturing Reshoring?" Journal of Global Operations and Strategic Sourcing 11 (1): 79-122. doi:10.1108/JGOSS-02-2017-0004.

Bentes, Alexandre Veronese, Jorge Carneiro, Jorge Ferreira da Silva, and Herbert Kimura. 2012. "Multidimensional Assessment of Organizational Performance: Integrating BSC and AHP." Journal of Business Research 65 (12): 1790-1799. doi:10.1016/j.jbusres.2011.10.039.

Bertrand, Olivier. 2011. "What Goes around, Comes around: Effects of Offshore Outsourcing on the Export Performance of Firms." Journal of International Business Studies 42 (2): 334-344. doi:10.1057/jibs.2010.26.

Brandon-Jones, Emma, Marie Dutordoir, Joao Quariguasi Frota Neto, and Brian Squire. 2017. "The Impact of Reshoring Decisions on Shareholder Wealth." Journal of Operations Management 49-51 (March): 31-36. doi:10.1016/j.jom.2016.12.002.

Chai, Junyi, James N.K. Liu, and Eric W.T. Ngai. 2013. "Application of Decision-Making Techniques in Provider Selection: A Systematic Review of Literature." Expert Systems with Applications 40 (10): 3872-3885. doi:10.1016/j.eswa.2012.12.040.

Chirulescu, Ana. 2017. AeroSpace and Defence Industries Association of Europe (ASD) Overview. Brussels. http://www.asd-europe.org/content/default.asp?PagelD=7.

Choi, A. C K, D. S K Chan, and A. M F Yuen. 2002. "Application of Virtual Assembly Tools for Improving Product Design." International Journal of Advanced Manufacturing Technology 19 (5): 377-383. doi:10.1007/s001700200027.

Denning, Stephen. 2013. "What Went Wrong at Boeing." Strategy \& Leadership 41 (3): 3641. doi:10.1108/10878571311323208.

Dey, Prasanta Kumar, and Walid Cheffi. 2013. "Green Supply Chain Performance Measurement Using the Analytic Hierarchy Process: A Comparative Analysis of Manufacturing Organisations." Production Planning \& Control 24 (8-9): 702-720. doi:10.1080/09537287.2012.666859.

Di Gregorio, Dante, Martina Musteen, and Douglas E. Thomas. 2009. "Offshore Outsourcing as a Source of International Competitiveness for SMEs." Journal of International Business Studies 40 (6): 969-988. doi:10.1057/jibs.2008.90.

Di Mauro, Carmela, Luciano Fratocchi, Guido Orzes, and Marco Sartor. 2018. "Offshoring and Backshoring: A Multiple Case Study Analysis." Journal of Purchasing and Supply Management 24 (108): 134. doi:10.1016/j.pursup.2017.07.003.

Dietrich, David M., and Elizabeth A. Cudney. 2011. "Methods and Considerations for the Development of Emerging Manufacturing Technologies into a Global Aerospace Supply Chain." International Journal of Production Research 49 (10): 2819-2831. doi:10.1080/00207541003801275.

Dolgui, Alexandre, and Jean Marie Proth. 2013. "Outsourcing: Definitions and Analysis." International Journal of Production Research 51 (23-24): 6769-6777. doi:10.1080/00207543.2013.855338.

Ecorys. 2009. FWC Sector Competitiveness Studies - Competitiveness of the EU Aerospace Industry with Focus on: Aeronautics Industry. Within the Framework Contract of Sectoral Competitiveness Studies - ENTR/06/054. Munich. 
doi:10.2769/33524.

Ellram, Lisa M., Wendy L. Tate, and Corey Billington. 2008. "Offshore Outsourcing of Professional Services: A Transaction Cost Economics Perspective." Journal of Operations Management 26 (2): 148-163. doi:10.1016/j.jom.2007.02.008.

Engblom, Janne, Tomi Solakivi, Juuso Töyli, and Lauri Ojala. 2012. "Multiple-Method Analysis of Logistics Costs." International Journal of Production Economics 137 (1): 29-35. doi:10.1016/j.ijpe.2012.01.007.

Fratocchi, Luciano, Alessandro Ancarani, Paolo Barbieri, Carmela Di Mauro, Guido Nassimbeni, Marco Sartor, Matteo Vignoli, and Andrea Zanoni. 2016. "Motivations of Manufacturing Reshoring: An Interpretative Framework." International Journal of Physical Distribution \& Logistics Management 46 (2): 98-127. doi:10.1108/IJPDLM-062014-0131.

Giannakis, Mihalis, and Thanos Papadopoulos. 2016. "Supply Chain Sustainability: A Risk Management Approach." International Journal of Production Economics 171: 455-470. doi:10.1016/j.ijpe.2015.06.032.

Gunasekaran, Angappa, and Zahir Irani. 2010. "Modelling and Analysis of Outsourcing Decisions in Global Supply Chains." International Journal of Production Research 48 (2): 301-304. doi:10.1080/00207540903174775.

GVR. 2014. Engineering Services Outsourcing (ESO) Market Analysis And Segment Forecasts To 2020. San Francisco.

Hartman, Paul L., Jeffrey A. Ogden, Joseph R. Wirthlin, and Benjamin T. Hazen. 2017.

"Nearshoring, Reshoring, and Insourcing: Moving beyond the Total Cost of Ownership Conversation." Business Horizons 60 (3). "Kelley School of Business, Indiana University": 363-373. doi:10.1016/j.bushor.2017.01.008.

Herath, Tejaswini, and Rajiv Kishore. 2009. "Offshore Outsourcing: Risks, Challenges, and Potential Solutions." Information Systems Management 26 (January): 312-326. doi:10.1080/10580530903245549.

Ihrig, Sebastian, Alessio Ishizaka, and Alwine Mohnen. 2017. "Target Setting for Indirect Processes: A New Hybrid Method for the Continuous Improvement Management of Indirect Processes." Production Planning \& Control 28 (3): 220-231. doi:10.1080/09537287.2016.1254830.

Isaksson, Raine. 2005. "Economic Sustainability and the Cost of Poor Quality." Corporate Social Responsibility and Environmental Management 12 (4): 197-209. doi:10.1002/csr.85.

Ishizaka, Alessio. 2008. "A Multicriteria Approach with AHP and Clusters for Provider Selection." In 15th International Annual EurOMA Conference.

Ishizaka, Alessio. 2014. "Comparison of Fuzzy Logic, AHP, FAHP and Hybrid Fuzzy AHP for New Provider Selection and Its Performance Analysis." International Journal of Integrated Supply Management 9 (1/2): 1-22.

Ishizaka, Alessio, and Rebecca Blakiston. 2012. "The 18 C's Model for a Successful Long -Term Outsourcing Arrangement." Industrial Marketing Management 41 (7): 1071_ 1080.

Ishizaka, Alessio, and Maynard Gordon. 2017. "MACBETHSort: A Multiple Criteria Decision Aid Procedure for Sorting Strategic Products." Journal of the Operational Research Society 68 (1): 53-61. doi:10.1057/s41274-016-0002-9.

Ishizaka, Alessio, and Ashraf Labib. 2011. "Selection of New Production Facilities with the Group Analytic Hierarchy Process Ordering Method." Expert Systems with Applications 38 (6): 7317-7325. doi:10.1016/j.eswa.2010.12.004.

Ishizaka, Alessio, and Markus Lusti. 2006. "How to Derive Priorities in AHP: A Comparative Study." Central European Journal of Operations Research 14 (4): 387-400. doi:10.1007/s10100-006-0012-9.

Ishizaka, Alessio, and Philippe Nemery. 2013. Multi-Criteria Decision Analysis. Chichester, 
UK: John Wiley \& Sons Ltd. doi:10.1002/9781118644898.

Ishizaka, Alessio, and Philippe Nemery. 2014. "Assigning Machines to Incomparable Maintenance Strategies with ELECTRE-SORT." Omega (United Kingdom) 47: 45-59. doi:10.1016/j.omega.2014.03.006.

Ishizaka, Alessio, Craig Pearman, and Philippe Nemery. 2012. "AHPSort: An AHP-Based Method for Sorting Problems." International Journal of Production Research 50 (17): 4767-4784. doi:10.1080/00207543.2012.657966.

Kahraman, Cengiz, Ahmet Beskese, and Ihsan Kaya. 2010. "Selection among ERP Outsourcing Alternatives Using a Fuzzy Multi-Criteria Decision Making Methodology." International Journal of Production Research 48 (2): 547-566. doi:10.1080/00207540903175095.

Kasirian, M. N., and R. M. Yusuff. 2013. "An Integration of a Hybrid Modified TOPSIS with a PGP Model for the Provider Selection with Interdependent Criteria." International Journal of Production Research 51 (4): 1037-1054. doi:10.1080/00207543.2012.663107.

Kaur, Harpreet, Surya Prakash Singh, and Abhijit Majumdar. 2018. "Modelling Joint Outsourcing and Offshoring Decisions." International Journal of Production Research 7543 (May): 1-32. doi:10.1080/00207543.2018.1471245.

Khan, N., W.L. Currie, V. Weerakkody, and B. Desai. 2003. "Evaluating Offshore IT Outsourcing in India: Provider and Customer." In 36th Annual Hawaii International Conference on System Sciences, 2003. Proceedings of The, 10 pp. Hawaii, USA: IEEE. doi:10.1109/HICSS.2003.1174617.

Kumar, S., and J. Wilson. 2009. "A Manufacturing Decision Framework for Minimizing Inventory Costs of a Configurable Off-Shored Product Using Postponement." International Journal of Production Research 47 (1): 143-162. doi:10.1080/00207540701477792.

Lahiri, Somnath, and Ben L. Kedia. 2011. "Co-Evolution of Institutional and Organizational Factors in Explaining Offshore Outsourcing." International Business Review 20 (3): 252-263. doi:10.1016/j.ibusrev.2011.01.005.

Lee, Hau L., and C. Billington. 1992. "Managing Supply Chain Inventory: Pitfalls and Opportunities." Corey Sloan Management Review 33 (3): 65-73.

Lin, Lun Hao, Li Chun Chen, and Yu Cheng Hsiao. 2011. "A Note on a Study of an Integrated Inventory with Controllable Lead Time." International Journal of Production Research 49 (15): 4727-4733. doi:10.1080/00207543.2010.501349.

Lineberger, Robin S., and A. Hussain. 2017. 2017 Global Aerospace and Defense Sector Financial Performance Study Defense Subsector Expands, While Commercial Aerospace Growth Slows Down. London. https://www2.deloitte.com/content/dam/Deloitte/global/Documents/consumer-industrialproducts/gx-cip-global-aerospace-defense-financial-performance-study.pdf.

Lolli, F., A. Ishizaka, and R. Gamberini. 2014. "New AHP-Based Approaches for MultiCriteria Inventory Classification." International Journal of Production Economics 156 (October): 62-74. doi:10.1016/j.ijpe.2014.05.015.

López, Cristina, and Alessio Ishizaka. 2017a. "GAHPSort: A New Group Multi-Criteria Decision Method for Sorting a Large Number of the Cloud-Based ERP Solutions." Computers in Industry 92-93: 12-24. doi:10.1016/j.compind.2017.06.007.

López, Cristina, and Alessio Ishizaka. 2017b. "A Hybrid FCM-AHP Approach to Predict Impacts of Offshore Outsourcing Location Decisions on Supply Chain Resilience." Journal of Business Research, no. September (October): 0-1. doi:10.1016/j.jbusres.2017.09.050.

Lowson, Robert H. 2002. "Assessing the Operational Cost of Offshore Sourcing Strategies." International Journal of Logistics Management 13 (2): 79. doi:10.1108/09574090210806441. 
Manning, Stephan, A. Lewin, and Marc Schuerch. 2011. "The Stability of Offshore Outsourcing Relationships." Management International Review 51 (3): 381-406. doi:10.1007/s11575-011-0081-4.

Marion, T. J., H. J. Thevenot, and T. W. Simpson. 2007. "A Cost-Based Methodology for Evaluating Product Platform Commonality Sourcing Decisions with Two Examples." International Journal of Production Research 45 (22): 5285-5308. doi:10.1080/00207540600710970.

Martínez-Jurado, Pedro José, and José Moyano-Fuentes. 2014. "Lean Management, Supply Chain Management and Sustainability: A Literature Review." Journal of Cleaner Production 85 (December): 134-150. doi:10.1016/j.jclepro.2013.09.042.

Miccoli, Francesco, and Alessio Ishizaka. 2017. "Sorting Municipalities in Umbria According to the Risk of Wolf Attacks with AHPSort II." Ecological Indicators 73: 741-755. doi:10.1016/j.ecolind.2016.10.034.

Mihalache, Mashiho, and Oli R Mihalache. 2015. "A Decisional Framework of Offshoring: Integrating Insights from 25 Years of Research to Provide Direction for Future." Decision Sciences 47 (6): 1103-1149. doi:10.1111/deci.12206.

Millet, Ido. 1997. "The Effectiveness of Alternative Preference Elicitation Methods in the Analytic Hierarchy Process." Jornal of Multi-Criteria Decision Analysis 6 (February 1996): 41-51. doi:10.1002/(SICI)1099-1360(199701)6:1<41::AID-MCDA122>3.3.CO;24.

Modak, Mousumi, Khanindra Pathak, and Kunal Kanti Ghosh. 2017. "Performance Evaluation of Outsourcing Decision Using a BSC and Fuzzy AHP Approach: A Case of the Indian Coal Mining Organization." Resources Policy 52 (June): 181-191. doi:10.1016/j.resourpol.2017.03.002.

Mohammadzadeh, A., A. Rezazadeh, S. Nazari-Shirkouhi, M. Ghadamyari, and M. R. Dalvand. 2011. "A Performance Measurement System under Activity Based Costing for Advanced Manufacturing Systems by an Integrated Fuzzy AHP-Fuzzy TOPSIS Approach." Scientific Research and Essays 6 (22): 4856-4866. doi:10.5897/SRE11.1322.

Mousseau, V., R. Slowinski, and P. Zielniewicz. 2000. "A User-Oriented Implementation of the ELECTRE-TRI Method Integrating Preference Elicitation Support." Computers and Operations Research 27 (7-8): 757-777. doi:10.1016/S0305-0548(99)00117-3.

Mukherjee, D, A S Gaur, and A Datta. 2013. "Creating Value through Offshore Outsourcing: An Integrative Framework." Journal of International Management 19 (4): 377-389. doi:10.1016/j.intman.2013.03.015.

Nakatsu, Robbie T., and Charalambos L. Iacovou. 2009. "A Comparative Study of Important Risk Factors Involved in Offshore and Domestic Outsourcing of Software Development Projects: A Two-Panel Delphi Study." Information and Management 46 (1): 57-68. doi:10.1016/j.im.2008.11.005.

Nemery, Philippe, Alessio Ishizaka, Mauricio Camargo, and Laure Morel. 2012. "Enriching Descriptive Information in Ranking and Sorting Problems with Visualizations Techniques." Journal of Modelling in Management 7 (2): 130-147. doi:10.1108/17465661211242778.

Nemery, Philippe, and Claude Lamboray. 2008. "Flow Sort: A Flow-Based Sorting Method with Limiting or Central Profiles." Top 16 (1): 90-113. doi:10.1007/s11750-007-0036-x.

Nieto, María Jesús, and Alicia Rodríguez. 2011. "Offshoring of RD: Looking Abroad to Improve Innovation Performance." Journal of International Business Studies 42 (3): 345-361. doi:10.1057/jibs.2010.59.

Por, Han-Hui, and David V. Budescu. 2017. "Eliciting Subjective Probabilities through PairWise Comparisons." Journal of Behavioral Decision Making 30 (2): 181-196. doi:10.1002/bdm.1929.

Resta, B., S. Dotti, P. Gaiardelli, and A. Boffelli. 2017. "How Lean Manufacturing Affects the 
Creation of Sustainable Value: An Integrated Model." International Journal of

Automation Technology 11 (4): 10-14. doi:10.20965/ijat.2017.p0542.

Rottman, Joseph W., and Mary C. Lacity. 2006. "Proven Practices for Effectively Offshoring IT Work." MIT Sloan Management Review 47 (3): 56-63.

http://sfx.cranfield.ac.uk/cranfield?url_ver=Z39.88-

2004\&rft_val_fmt=info:ofi/fmt:kev:mtx:journal\&genre=article\&sid=ProQ:ProQ\%253Aabi global\&atitle=Proven+Practices+for+Effectively+Offshoring+IT+Work\&title=MIT+Sloan+ Management+Review\&issn=15329194\&date $=200$.

Saaty, Thomas L. 1977. "A Scaling Method for Priorities in Hierarchical Structures." Journal of Mathematical Psychology 15 (3): 234-281. doi:10.1016/0022-2496(77)90033-5.

Sevkli, Mehmet. 2010. "An Application of the Fuzzy ELECTRE Method for Provider Selection." International Journal of Production Research 48 (12): 3393-3405. doi:10.1080/00207540902814355.

Sivapornpunlerd, Nathavat, and Siri-on Setamanit. 2014. "Provider Performance Evaluation: A Case Study of Thai Offshore Oil \& Gas Exploration and Production Company." In Proceedings of ASBBS, 21:647-660. Las Vegas, USA.

Smite, Darja, Ricardo Britto, and Rini van Solingen. 2017. "Calculating the Extra Costs and the Bottom-Line Hourly Cost of Offshoring." In 2017 IEEE 12th International Conference on Global Software Engineering (ICGSE), 96-105. IEEE. doi:10.1109/ICGSE.2017.12.

Stentoft, Jan, Ole Stegmann Mikkelsen, Jesper Kronborg Jensen, and Christopher Rajkumar. 2018. "Performance Outcomes of Offshoring, Backshoring and Staying at Home Manufacturing." International Journal of Production Economics 199 (April 2017). Elsevier Ltd: 199-208. doi:10.1016/j.jpe.2018.03.009.

Steven, Adams B., Yan Dong, and Thomas Corsi. 2014. "Global Sourcing and Quality Recalls: An Empirical Study of Outsourcing-Provider Concentration-Product Recalls Linkages." Journal of Operations Management 32 (5): 241-253. doi:10.1016/j.jom.2014.04.003.

Stringfellow, Anne, Mary B. Teagarden, and Winter Nie. 2008. "Invisible Costs in Offshoring Services Work." Journal of Operations Management 26 (2): 164-179. doi:10.1016/j.jom.2007.02.009.

Tate, Wendy L., Lisa M. Ellram, Tobias Schoenherr, and Kenneth J. Petersen. 2014. "Global Competitive Conditions Driving the Manufacturing Location Decision." Business Horizons 57 (3). "Kelley School of Business, Indiana University": 381-390. doi:10.1016/j.bushor.2013.12.010.

Tersine, Richard J. 1993. Principles of Inventory and Materials Management. 4th ed. New Jersey: Prentice Hall.

Wadhwa, Vijay, and A. Ravi Ravindran. 2007. "Vendor Selection in Outsourcing." Computers and Operations Research 34 (12): 3725-3737. doi:10.1016/j.cor.2006.01.009.

Walker, Professor Helen, Professor Stefan Seuring, Professor Joseph Sarkis, and Professor Robert Klassen. 2014. "Sustainable Operations Management: Recent Trends and Future Directions." International Journal of Operations \& Production Management 34 (5). doi:10.1108/IJOPM-12-2013-0557.

WCIR. 2013. Aerospace Manufacturing Transfer Systems. www.wipro.com/documents/insights/aerospace-manufacturingtransfersystems.\%0Apdf.

Weerakkody, Vishanth, and Zahir Irani. 2010. "A Value and Risk Analysis of Offshore Outsourcing Business Models: An Exploratory Study." International Journal of Production Research 48 (2): 613-634. doi:10.1080/00207540903175160.

Whitaker, Jonathan, Sanjeev Kumar, and M. S. Krishnan. 2018. "How Client Capabilities, Vendor Configuration, and Location Impact BPO Outcomes." Journal of Computer 
Information Systems 58 (2): 180-191. doi:10.1080/08874417.2016.1220241.

Wijnmalen, Diederik J.D. 2007. "Analysis of Benefits, Opportunities, Costs, and Risks (BOCR) with the AHP-ANP: A Critical Validation." Mathematical and Computer Modelling 46 (7-8): 892-905. doi:10.1016/j.mcm.2007.03.020.

Wu, Desheng Dash. 2010. "A Systematic Stochastic Efficiency Analysis Model and Application to International Provider Performance Evaluation." Expert Systems with Applications 37 (9): 6257-6264. doi:10.1016/j.eswa.2010.02.097.

Yadav, Gunjan, Sachin Kumar Mangla, Sunil Luthra, and Suresh Jakhar. 2018. "Hybrid BWM-ELECTRE-Based Decision Framework for Effective Offshore Outsourcing Adoption: A Case Study." International Journal of Production Research 7543 (May): 119. doi:10.1080/00207543.2018.1472406.

Yang, Jin-Shan, and Jason Chao-Hsien Pan. 2004. "Just-in-Time Purchasing: An Integrated Inventory Model Involving Deterministic Variable Lead Time and Quality Improvement Investment." International Journal of Production Research 42 (5): 853 863. doi:10.1080/00207540310001632448.

Zheng, Songyue, Yi Liu, Yuan Li, and Liang Wang. 2018. "Conjunct Roles of Client and Vendor Control in Offshore-Outsourced Project Performance." International Journal of Production Research 7543: 1-19. doi:10.1080/00207543.2018.1433340. 


\section{Appendix. Extract of AHPSort questionnaire}

Circle one number per row below using the scale:

$1=$ Equal $3=$ Moderate $5=$ Strong $7=$ Very strong $9=$ Extreme

2, 4, 6, 8 are intermediate values

Question 1. Compare the relative performance of offshore providers with regard to the limiting profiles of logistic cost criterion.

\section{Provider 1}

\begin{tabular}{|l|lllllllllllllllll|l|}
\hline Provider 1 & 9 & 8 & 7 & 6 & 5 & 4 & 3 & 2 & 1 & 2 & 3 & 4 & 5 & 6 & 7 & 8 & 9 & $\begin{array}{l}\text { Limiting profile } \\
\text { low-medium }\end{array}$ \\
\hline Provider 1 & 9 & 8 & 7 & 6 & 5 & 4 & 3 & 2 & 1 & 2 & 3 & 4 & 5 & 6 & 7 & 8 & 9 & $\begin{array}{l}\text { Limiting profile } \\
\text { medium-high }\end{array}$ \\
\hline $\begin{array}{l}\text { Limiting } \\
\text { profile low- } \\
\text { medium }\end{array}$ & 9 & 8 & 7 & 6 & 5 & 4 & 3 & 2 & 1 & 2 & 3 & 4 & 5 & 6 & 7 & 8 & 9 & $\begin{array}{l}\text { Limiting profile } \\
\text { medium-high }\end{array}$ \\
\hline
\end{tabular}

\section{Provider 2}

\begin{tabular}{|l|lllllllllllllllll|l|}
\hline Provider 2 & 9 & 8 & 7 & 6 & 5 & 4 & 3 & 2 & 1 & 2 & 3 & 4 & 5 & 6 & 7 & 8 & 9 & $\begin{array}{l}\text { Limiting profile } \\
\text { low-medium }\end{array}$ \\
\hline Provider 2 & 9 & 8 & 7 & 6 & 5 & 4 & 3 & 2 & 1 & 2 & 3 & 4 & 5 & 6 & 7 & 8 & 9 & $\begin{array}{l}\text { Limiting profile } \\
\text { medium-high }\end{array}$ \\
\hline $\begin{array}{l}\text { Limiting } \\
\text { profile low- } \\
\text { medium }\end{array}$ & 9 & 8 & 7 & 6 & 5 & 4 & 3 & 2 & 1 & 2 & 3 & 4 & 5 & 6 & 7 & 8 & 9 & $\begin{array}{l}\text { Limiting profile } \\
\text { medium-high }\end{array}$ \\
\hline
\end{tabular}

\section{Provider 3}

\begin{tabular}{|l|lllllllllllllllll|l|}
\hline Provider 3 & 9 & 8 & 7 & 6 & 5 & 4 & 3 & 2 & 1 & 2 & 3 & 4 & 5 & 6 & 7 & 8 & 9 & $\begin{array}{l}\text { Limiting profile } \\
\text { low-medium }\end{array}$ \\
\hline Provider 3 & 9 & 8 & 7 & 6 & 5 & 4 & 3 & 2 & 1 & 2 & 3 & 4 & 5 & 6 & 7 & 8 & 9 & $\begin{array}{l}\text { Limiting profile } \\
\text { medium-high }\end{array}$ \\
\hline $\begin{array}{l}\text { Limiting } \\
\text { profile low- } \\
\text { medium }\end{array}$ & 9 & 8 & 7 & 6 & 5 & 4 & 3 & 2 & 1 & 2 & 3 & 4 & 5 & 6 & 7 & 8 & 9 & $\begin{array}{l}\text { Limiting profile } \\
\text { medium-high }\end{array}$ \\
\hline
\end{tabular}

\section{Provider 4}

\begin{tabular}{|l|lllllllllllllllll|l|}
\hline Provider 4 & 9 & 8 & 7 & 6 & 5 & 4 & 3 & 2 & 1 & 2 & 3 & 4 & 5 & 6 & 7 & 8 & 9 & $\begin{array}{l}\text { Limiting profile } \\
\text { low-medium }\end{array}$ \\
\hline Provider 4 & 9 & 8 & 7 & 6 & 5 & 4 & 3 & 2 & 1 & 2 & 3 & 4 & 5 & 6 & 7 & 8 & 9 & $\begin{array}{l}\text { Limiting profile } \\
\text { medium-high }\end{array}$ \\
\hline $\begin{array}{l}\text { Limiting } \\
\text { profile low- } \\
\text { medium }\end{array}$ & 9 & 8 & 7 & 6 & 5 & 4 & 3 & 2 & 1 & 2 & 3 & 4 & 5 & 6 & 7 & 8 & 9 & $\begin{array}{l}\text { Limiting profile } \\
\text { medium-high }\end{array}$ \\
\hline
\end{tabular}

